\title{
O esporte e a competição na educação física escolar: perspectivas educacionais a partir dos conceitos da pedagogia do esporte
}

\author{
Sport and competition in School Physical Education: educational perspectives from the sport \\ pedagogy concepts
}
Deporte y competición en la educación física escolar: perspectivas educativas desde los conceptos de pedagogía deportiva

\author{
Flaviane Faria ${ }^{\mathrm{I}}$, André Felipe Caregnato ${ }^{\mathrm{II}}$, Fernando Renato Cavichiolli ${ }^{\mathrm{III}}$
}

\begin{abstract}
Resumo
O presente estudo tem como objetivo investigar as possibilidades educacionais do esporte e da competição na Educação Física escolar. Para isso, este estudo se utiliza dos preceitos teóricos da Pedagogia do Esporte. Identificou-se que a Pedagogia do Esporte apresenta estratégias de desenvolver o esporte e a competição na Educação Física escolar, no entanto, diagnosticou-se lacunas. Conclui-se que o fracasso e o sucesso dos conteúdos do esporte e da competição dependem diretamente dos princípios pedagógicos utilizados pelo professor. Há necessidade da elaboração de mais estudos de caráter práticos, sobretudo, relacionados às modalidades individuais.
\end{abstract}

Palavras-chave: Esporte; Competição; Educação Física e Treinamento; Pedagogia

\begin{abstract}
The present study aims to investigate the educational possibilities of sport and competition in School Physical Education. For this, this study uses the theoretical precepts from Sports Pedagogy. It was identified that the Sport Education presents strategies to develop the sport and competition in School Physical Education, however, it was acknowledged gaps. It follows that the failure and successful of sport content and competition depend directly on pedagogical principles used by the teacher. There is need for development of more practical character studies, mainly related to individual sports.
\end{abstract}

Keywords: Sport; Competition; Physical Education and Training; Pedagogy

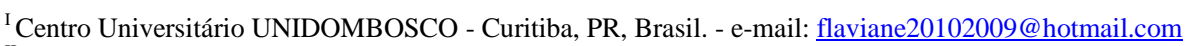

II Universidade Federal do Paraná - UFPR - Curitiba, PR, Brasil. Endereço: Av. Presidente Wenceslau Braz, 1172 , Bairro Guaíra, Curitiba - PR, CEP: 81010000 - e-mail: andre.caregnato@hotmail.com

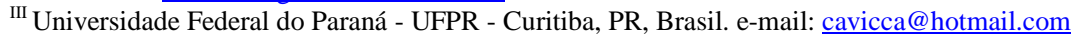




\section{Resúmen}

Este estudio tiene como objetivo investigar las posibilidades educativas del deporte y de la competencia en la Educación Física escolar. Para esto, este estudio utiliza los preceptos teóricos de la Pedagogía del Deporte. Se identificó que la pedagogía deportiva presenta estrategias para desarrollar el deporte y la competencia en la educación física escolar, sin embargo, se diagnosticaron lagunas. Se concluye que el fracaso y el éxito del contenido deportivo y de competición dependen directamente de los principios pedagógicos utilizados por el profesor. Se necesitan más estudios prácticos, especialmente relacionados con las modalidades individuales.

Palavras clave: Deportes; Competición; Educación Física y Entrenamiento; Pedagogía

\section{Introdução}

Este estudo, com auxílio da teoria da Pedagogia do Esporte, apresenta uma discussão sobre a presença do esporte e da competição na Educação Física escolar. Assim, baseando-se em princípios pedagógicos, este trabalho poderá auxiliar os professores e pedagogos esportivos a identificar possibilidades de desenvolver os conteúdos esportivos e competitivos na Educação Física.

Segundo Bento (2006), a Pedagogia do Esporte tem origem da pedagogia geral e da ciências do desporto, tendo seus conceitos muito difundidos em Portugal, assim, também é denominada Pedagogia do Desporto (Portugal). Além disso, trata do relacionamento entre o Esporte e a Educação, sendo ela direcionada para dar os fundamentos humanos e teóricos para a prática dos esportes (GALATTI; PAES, 2006).

A Pedagogia do Esporte, embora seja uma linha de investigação ainda jovem, vem se consolidando nas últimas décadas como significativa área de conhecimento no interior das ciências do esporte, gerando significativos avanços nas reflexões acerca de diferentes manifestações constituintes da Cultura Corporal, de temas como, metodologias de ensino e treinamento de esportes, aprendizagem, didática, análises de jogos, compreensão da competição e do esporte (REVERDITO; SCAGLIA; MONTAGNER, 2013).

No que se refere à função da Educação Física escolar - aquela trabalhada nas aulas curriculares de acordo com os níveis e dimensões de ensino, contendo diversos conteúdos pré-determinados, como, futsal, vôlei e lutas -, ela deve preocupar-se com a formação integral dos alunos, intervindo nos aspectos motor, cognitivo, afetivo e social (BARROSO; DARIDO, 2009). Para isso, compreende-se como imprescindível à estruturação de uma prática pedagógica - maneiras e procedimentos de trabalho - que possibilitem tais objetivos; nesse sentido, o esporte é entendido como um caminho possível (GALATTI; PAES, 2006).

O esporte na escola pode ser representado pelo esporte de rendimento no contexto escolar (BRACHT; ALMEIDA, 2003), porém, seria o ideal que ele fosse desenvolvido nesse ambiente com um olhar multicultural, numa diversidade de manifestações, além do esporte que possui maior visibilidade (STIGGER, 2001) - isso, aumentaria as possibilidades e competências esportivas dos alunos (VARGAS; MORISSO; GONZÁLEZ, 2017).

O esporte é considerado um dos maiores fenômenos socioculturais da atualidade, tornando-se relevante sua prática e reflexão nos diferentes ambientes que ele está presente, como na educação formal (CARLAN; KUNZ; 
FENSTERSEIFER, 2012; MACHADO; GALATTI; PAES, 2014). Além de ser uns dos conteúdos mais tradicionais da Educação Física, no ambiente escolar encontra-se uma das maiores manifestações das práticas esportivas, o problema é que a escola ainda não acredita na possibilidade e na função educativa do esporte, sobretudo da competição (PAES, 1996).

Nesse sentido, a competição no âmbito escolar, por muito tempo esteve alimentada à base de contradições, reféns da apresentação de seus aspectos positivos, de um lado, e dos negativos, de outro (REVERDITO et al., 2008). A competição é considerada um elemento fundamental do esporte, que dá sentido à sua existência, pois é na competição que a manifestação do esporte se realiza em sua plenitude (SCAGLIA; GOMES, 2005). Por isso, deve ser entendida como um fenômeno inerente à existência do esporte, consequentemente, a competição precisa ser tratada enquanto conteúdo da Educação Física escolar (BELOTTO; REVERDITO, 2011).

A partir disso, surge a seguinte questão para o presente estudo: como deve ser desenvolvido o esporte e a competição na Educação Física escolar a partir dos conceitos da Pedagogia do Esporte? Dessa forma, este trabalho tem como objetivo geral investigar as possibilidades educacionais do esporte e da competição na Educação Física escolar, orientados por condutas e princípios da Pedagogia do Esporte.

Para iniciar o debate, no primeiro momento será discutido a relação imprecisa entre Educação Física/Esporte. Em seguida, destaca-se a função das competições esportivas; do jogo como importante recurso pedagógico; e por fim o papel do professor nesse processo. É importante ressaltar que não há, neste trabalho, a defesa da hegemonia do esporte, em detrimento aos outros conteúdos obrigatórios da Educação Física, nem a negação deste, mas, apenas de destacar a necessidade da adoção de práticas pedagógicas adequadas nas aulas de Educação Física no ensino do Esporte e da competição.

\section{A educação física e o esporte: uma relação de ambiguidades}

Para compreender o momento atual do Esporte como conteúdo da Educação Física faz-se necessário estudá-lo em seus diferentes ambientes e, portanto, considerar alguns aspectos da sua história no contexto escolar, identificando as influências e as transformações que ocorreram nessa relação.

Bracht e Almeida (2003) e Betti (1999) explicam que a relação da Educação Física com o Esporte foi intensificada a partir da década de 70, quando a Educação Física passou a atender os interesses do sistema esportivo, funcionando como o alicerce do esporte de rendimento do país.

O discurso na década de 70 era baseado na possibilidade de um quadro de futuros atletas olímpicos através das aulas de Educação Física, com isso suas aulas tornaram-se quase que totalmente submissa às exigências do sistema esportivo nacional, e a padronização técnica dos gestos e rendimentos esportivos passaram a definir os seus conteúdos. Na década de 80 , iniciou-se um período de crítica e de denúncias sobre a hegemonia e o modelo de esporte praticado nas aulas de Educação Física (STIGGER, 2001). 
Diante disso, Carlan, kunz e Fensterseifer (2012) destacam que a década de 80 foi marcante para a Educação Física brasileira, pois ocorreu um profundo questionamento no que diz respeito a seus objetivos, sentidos, valores, diretrizes e aos instrumentos de ação didático-pedagógica norteadores da prática pedagógica do professor. Esse período também é evidenciado por Reverdito, Scaglia e Montagner (2013), os autores explicam que ocorreu uma efervescência nas reflexões sobre a Educação Física no período de 1980 e 1990, o esporte, e, mais particularmente, a competição foram temas renegados, surgindo propostas que declaradamente os negavam, ou mesmo desqualificavam.

Com a criação dos Parâmetros Curriculares Nacionais (PCN's) em 1997, houve uma sistematização nos objetivos, conteúdos e processos de ensino e aprendizagem na Educação Física. Buscou-se justamente reverter o quadro histórico de exclusão e da seleção entre indivíduos aptos e inaptos para as práticas corporais, resultante da excessiva valorização do desempenho e da eficiência (BARROSO; DARIDO, 2009). Dessa forma, os conteúdos da Educação Física deveriam valorizar e desenvolver os valores educacionais das práticas corporais.

O esporte oferecido na Educação Física, em muitos casos é de forma fragmentada, evidenciando durante a prática pedagógica a busca de automatismos e gestos estereotipados próprios dos esportes hegemônicos. Com essa finalidade, a Educação Física acaba por se tornar uma escolinha de determinadas modalidades deixando de lado o seu sentido educacional. O esporte ensinado nas escolas enquanto cópia do esporte de rendimento resulta na vivência de sucesso para uma minoria (BRACHT; ALMEIDA, 2003).

Nesse sentido, Hirama e Montagner (2013) explicam que deverão ser diferentes os objetivos do esporte de rendimento e o esporte como conteúdo da Educação Física, pois enquanto no rendimento o principal objetivo é o desempenho máximo, no conteúdo da Educação Física, o objetivo é a aprendizagem, a socialização e o desenvolvimento o aluno.

Diante disso, Reverdito, Scaglia e Montagner (2013) destacam que ocorre um grande distanciamento entre a teoria e a prática, ou seja, a distância entre o que acredita estar sendo ensinado e como está sendo ensinado. A divergência entre o discurso e a prática também é apontada por Sadi (2013). Segundo o autor é realizado um discurso de princípios avançados incluindo promessas de mudança, mas a prática incoerente informa que o esporte educacional/escolar continua apresentando um ensino conservador.

Para Bracht e Almeida (2003) sem negar o potencial educativo do esporte, é preciso que o esporte passe por um trato pedagógico para que se torne um saber característico da escola. É necessário resgatar os valores educacionais do esporte, como o compromisso da solidariedade, do respeito humano, a importância do jogar como companheiro, e não contra o adversário. Além de enfatizar os jogos com regras implícitas e específicas para que seu aprendizado não finalize nos gestos técnicos (SOARES; MONTAGNER, 2013).

Segundo Barroso e Darido (2009) um dos principais problemas relacionados à realização de esporte escolar são as dúvidas quanto à sua função educacional, principalmente pelo fato de não ter um enfoque educativo claro, e não se perguntar para quem é o esporte. Portanto, torna-se importante à utilização dos fundamentos da Pedagogia 
do Esporte. Pois esta área da ciência esportiva não ignora a existência dos aspectos negativos do esporte e da competição, mas também reconhece os aspectos positivos e as várias possibilidades educacionais desses conteúdos quando desenvolvidos fundamentados em procedimentos metodológicos (MONTAGNER; SCAGLIA, 2013).

\section{Pedagogia do Esporte e as competições esportivas: muito além do ganhar e perder}

As novas tendências da Pedagogia do Esporte compreendem que ensinar o esporte deve estar vinculado com múltiplas possibilidades visando à formação humana e esportiva do sujeito.

Entre os assuntos que a Pedagogia do Esporte aborda, discutindo sua viabilidade e possibilidade educacional, está a competição (HIRAMA; MONTAGNER, 2013). Pois as influências históricas do esporte proporcionam a ideia de que a promoção de competições refere-se somente a treinamento e rendimento de equipes esportivas, sendo necessário um aprofundamento nas competições educacionais (SADI, 2008).

Para isso, a Pedagogia esportiva busca o rompimento da significação reducionista da competição, baseada na fundamentação de que o vencedor sobrepõe-se ao perdedor, oferecendo diferentes compreensões sobre a situação de vencer ou de ser vencido (BALBINO et al., 2013).

As competições escolares, mais especificamente na Educação Física, são constantemente alvo de diversas críticas. Pois, de acordo com Azevedo Junior (2008) são uma cópia da competição para adultos, e isso pode disseminar valores poucos construtivos à educação. No entanto, ao se discutir o ensino de esportes, não se deve descartar a necessidade de se ensinar a competir, pois a competição como conteúdo do planejamento do professor pode enriquecer e incrementar o processo de ensino (SCAGLIA; MEDEIROS; SADI, 2006).

Além disso, saber participar de contextos competitivos torna-se fundamental para poder viver em sociedade, considerando que a competição está presente nas mais variadas situações, por exemplo, para conseguir posição no trabalho (BALBINO et al., 2013). Sobre a presença da competição nas aulas de Educação Física Soares e Montagner (2013) destacam que as atividades competitivas não precisam ser banidas das aulas, o que deixaria de lado conteúdos de valor intrínsecos a essa prática.

Não existe esporte sem competição, mas isso não significa que os modelos de competição estereotipados da sociedade devam ser o exemplo seguido na escola (REVERDITO; SCAGLIA; MONTAGNER, 2013). Pois, os autores ainda destacam que o cenário em que se encontra as competições escolares precisam urgentemente de uma transformação, tornando-se necessário criar um ambiente facilitador de relações sociais, sustentado por princípios e procedimentos pedagógicos, tornando-se necessário uma reflexão sustentada na ação e uma ação sustentada na reflexão, para que rompa com esse modelo alienante e obsoleto de competição.

Em relação à problemática das práticas competitivas na escola, Balbino et al. (2013) e Galatti et al. (2008) afirmam que a competição não é o problema, o problema está na forma que seus conteúdos são desenvolvidos, e 
nos objetivos de quem a organiza, ou seja, o problema está na metodologia utilizada na sua organização e aplicação.

Os autores são unânimes na necessidade e na possibilidade das competições no interior da escola serem direcionadas por uma proposta de competição pedagógica que seja orientada por condutas e princípios pedagógicos (HIRAMA; MONTAGNER, 2013; SADI, 2008; GALATTI; PAES, 2006 ).

Nesse sentido, Montagner e Scaglia (2013) destacam que a construção do conceito de "Pedagogia da Competição" para os esportes de crianças e jovens, deve ser baseada em um pensamento em torno de maximizar os aspectos positivos e minimizar os aspectos negativos que certamente existem na competição esportiva. Por outro lado, Hirama e Montagner (2013) destacam que existem muitos autores que defendem a não estimulação da competição, justificando que esse componente, por si só, desenvolve valores negativos, como o egoísmo, a agressividade, $\mathrm{o}$ individualismo.

Em relação aos fatores positivos e negativos da competição, Soares e Montagner (2013) ressaltam que o fato de perder, dependendo da faixa etária pode gerar frustações. Por outro lado, deve-se ensinar a ganhar com humildade, enfatizando que a vitória nas atividades coletivas é o reflexo de uma equipe estruturada, confiante, que respeita os limites individuais de cada integrante do grupo e no individual é o resultado de superação, de disciplina e de desempenho. Considerando os aspectos negativos e positivos, se o esporte competitivo é bom ou ruim, Reverdito, Scaglia e Montagner (2013) afirmam que o esporte e a competição é aquilo que é feito dela.

Hirama e Montagner (2013) entendem que o sucesso na competição não é exclusividade dos vencedores, pois independente do resultado são estimulados importantes valores como a superação das frustações, a humildade, o esforço para superar os limites individuais e coletivos. Muitos discursos e ações que apenas apontam o lado negativo da competição, esquecem-se da capacidade das crianças superarem erros e conviverem com a frustração e o fracasso oriundos das mais variadas experiências. Sendo que essas sensações e experiências são extremamente importantes para o fortalecimento de várias atitudes, e também, para a formação de pessoas equilibradas e coerentes (MONTAGNER; SCAGLIA, 2013).

$\mathrm{Na}$ busca de novas alternativas de desenvolvimento das competições na escola, Scaglia, Medeiros e Sadi (2006) sugerem as competições pedagógicas e os festivais esportivos. Para os autores, elas precisam ser integrantes do projeto político pedagógico da escola, e as competições pedagógicas são as atividades tradicionais da cultura escolar. Enquanto os festivais esportivos são atividades de integração, de caráter mais lúdico, com maior participação e envolvimento dos pais na organização dos eventos. Os autores ressaltam que a presença de uma não exclui a outra, mas sugerem que os festivais sejam mais voltados às crianças de 7 a 12 anos de idade, e as competições pedagógicas para os adolescentes de 13 e 14 anos.

Em relação às novas possibilidades na arbitragem nas competições pedagógicas e festivais, Balbino et al. (2013) propõem que a arbitragem não represente apenas uma figura punitiva, mas também educativa, punindo as infrações que violem as regras do jogo, mas também explicando o porquê da punição. Referente à premiação, 
Montagner e Scaglia (2013) sugerem que todos os alunos participantes de competições pedagógicas nas escolas saiam premiados delas. Os autores entendem que cada aluno ou professor, em algum momento, obteve uma vitória, pessoal ou coletiva, e isso deve ser valorizado simbolicamente.

O importante é compreender a conduta pedagógica na iniciação como uma construção do jogar em que todos ganham, não pelos resultados de placar, mas pelos aprendizados, que passam por significações e tratamentos pedagógicos no jogo e na competição, e isso é possível até quando o placar é favorável ao adversário (BALBINO et al., 2013). A Educação Física como competição deve ser diluída na essência do jogo, que, por sua vez, passa de meio do ensino, a uma disputa festiva envolvendo aspectos de formação e desafio (SADI, 2013).

\section{0 jogo como um importante recurso pedagógico}

Nessa perspectiva, a Pedagogia do Esporte compreende o jogo como a principal ferramenta no ensino dos esportes e da competição. Ainda, a forma como o jogo é desenvolvido é o grande mobilizador nesse processo.

O jogo esportivo é um recurso pedagógico que melhor expressa as múltiplas determinações da competição e de suas possibilidades educacionais (SADI, 2013), pois no jogo as regras podem ser alteradas pelos jogadores, que não têm a obrigação de vencer, embora se mantenha a possibilidade de competir (GALATTI et al., 2008).

O jogo é um importante instrumento pedagógico na busca de uma continuidade do processo educativo, que a cada aula deve proporcionar uma aquisição gradual de conhecimentos (FREIRE, 2003). Sendo que o jogo e o esporte se confundem um no outro, pois ambos possuem uma mesma natureza (REVERDITO; SCAGLIA, 2007). Com isso, a Pedagogia do Esporte utiliza o jogo como a principal ferramenta pedagógica no ensino dos esportes competitivos.

A Pedagogia do Esporte vai além do aprendizado isolado de técnicas ou do jogo e seus fundamentos. A sua proposta de ensino do esporte deve levar os alunos a compreender a lógica do jogo, oportunizar o desenvolvimento da inteligência individual e coletiva, integrar a comunidade com a escola, estimular a preparação e avaliação dos jogos (SCAGLIA; MEDEIROS; SADI, 2006).

Ensinar pelo jogo é valorizar a complexidade do fenômeno esportivo e enfatizar o ensino pela totalidade de maneira sistêmica numa estrutura complexa de ações e problemas a serem resolvidos (GALATTI et al., 2008). O ensino dos esportes deve ocorrer através de pequenos jogos e jogos modificados, com ênfase na tática, na compreensão de “o que fazer?" para buscar o “como?" e "para que fazer?” (SADI, 2008). A compreensão, segundo os autores, estimula um processo de tomada de decisões pelos estudantes em relação ao que fazer (consciência tática) e ao como fazer (execução da habilidade). Além disso, compreender primeiro o jogo e, depois, preocupar-se com o ensino da técnica enriquece a própria função da técnica. 
Além disso, Venditti Jr. e Sousa (2008) entendem que o jogo promove o desenvolvimento afetivo-social e de princípios fundamentais como a cooperação, a participação, a convivência, a emancipação e a autoestima. Dessa forma, o aluno participa das atividades de maneira mais crítica e ativa, compreendendo melhor os elementos do jogo, estimulando a autonomia, além de aprender a respeitar as limitações dos demais participantes. Isso implica em formar a cidadania, a responsabilidade, a autonomia e a independência dentro das atividades de estímulo à consciência crítica e à inteligência nos jogos, ou seja, em uma ressignificação das competições (SADI, 2013).

Além da importância do jogo, a Pedagogia do Esporte também destaca a relevância do professor como o principal mediador no ensino das práticas esportivas competitivas, assim faz-se necessário identificar quais são possibilidades de intervenções referente à sua função.

\section{A função do professor no processo de ensino do esporte e da competição}

Atualmente a Educação Física escolar apresenta inúmeras possibilidades, embasadas em inúmeras tendências pedagógicas e procedimentos metodológicos. Nesse sentido, o professor tem a responsabilidade de identificar as ferramentas mais eficazes para oportunizar ao aluno o desenvolvimento completo. Os professores de Educação Física encontram dificuldades em modificar suas práticas pedagógicas no ensino do conteúdo Esportes, e não conseguem superar o paradigma da racionalidade instrumental. Muitos professores ainda optam por uma prática pedagógica baseada no ensino tradicional do esporte, reproduzindo em suas aulas a valorização dos movimentos fragmentados dos fundamentos técnicos (GALATTI; PAES, 2006).

Nesse aspecto de transformação, alguns estudos apresentam o modelo do Sport Education como uma possibilidade para enfrentar a visão reducionista e instrumental do esporte ensinado nas aulas de Educação Física escolar. Também, proporciona ao aluno uma vivência corporal que vai além da mera reprodução do esporte praticado, a partir de um ambiente de aprendizagem em que os praticantes desempenham diferentes funções nesse processo e, consequentemente, adquirem maiores conhecimentos, autonomia e gosto pelas aulas (GRAÇA; MESQUITA, 2007; VARGAS; MORISSO; GONZÁLEZ , 2017; VARGAS et al., 2018).

Neste modelo, o professor deve respeitar o conteúdo proposto e, principalmente, ensiná-lo de modo que todos os alunos desenvolvam um conjunto de saberes corporais e conceituais sobre o mesmo. No Sport Education, os discentes devem contribuir para o desenvolvimento das aulas, por exemplo, na organização e divisão das equipes; na divulgação do conteúdo e dos participantes; na participação e elaboração da competição; e, por fim, fazer com que a competição se torne um evento esportivo proveitoso para todos os envolvidos da escola (GRAÇA; MESQUITA, 2007; VARGAS; MORISSO; GONZÁLEZ , 2017; VARGAS et al., 2018).

Similarmente, outro estudo apresenta uma prática de caráter inovadora, reflexiva e crítica, envolvendo alunos da $5^{\mathrm{a}}$ a $8^{\mathrm{a}}$ séries, na unidade didática Futebol. Primeiramente, o professor optou por filmar as aulas iniciais, com a finalidade de conhecer a turma, observar os comportamentos técnicos e táticos de jogo, bem como montar 
equipes equilibradas para o Campeonato de Futebol - evento final do conteúdo em questão e, assim, definir objetivos a serem atingidos (CARLAN; KUNZ; FENSTERSEIFER, 2012) .

Nesse sentido, o professor desenvolvia suas aulas por meio de exercícios táticos e jogos situacionais (atividades criadas a partir de situações extraídas do jogo), para fornecer ao praticante maiores possibilidades de compreensão do jogo. Conjuntamente, os alunos deveriam assistir jogos de futebol e observar o comportamento dos jogadores, treinadores, árbitros, além disso, identificar a estrutura física esportiva dos seus bairros para uma posterior discussão em sala de aula dos temas pesquisados - com auxílio do professor (CARLAN; KUNZ; FENSTERSEIFER, 2012).

É importante destacar que nesses exemplos supracitados, o esporte não é tratado somente sob o viés instrumental, pois, as dimensões pedagógica e epistemológica da Cultura Corporal do Movimento estão articuladas. Toda ação educativa necessita ter uma fundamentação baseada em uma concepção teórica que a direcione; por isso, a prática pedagógica de qualquer professor deve ser planejada com uma pedagogia. Além disso, o professor deve possuir uma postura reflexiva; sua reflexão deve ser transformada em ação, procurando não reproduzir as formas tradicionais de competição, mas criar novos olhares sem perder o principal foco: competir (SOARES; MONTAGNER, 2013).

A Pedagogia do Esporte entende que o professor é o grande mediador no processo de aprendizagem de comportamentos e atitudes durante as competições esportivas (MONTAGNER; SCAGLIA, 2013; SADI, 2013). E na condição de mediador, o professor deve proporcionar um ambiente no qual o aluno possa se deparar com situações que irão guiá-lo para uma aprendizagem de comportamentos e atitudes.

A importância da função do professor é evidenciada pela Pedagogia do Esporte, pois entre as propostas de modificações pedagógicas e metodológicas, uma das fundamentais e mais importante está a modificação da postura do professor diante da competição. O professor também tem a função de elaborar uma diversidade de conteúdos e a estruturação de uma Pedagogia do Esporte que atenda aos interesses e necessidades do aluno (VENDITTI JR.; SOUZA, 2008). Paes (1996) destaca que o professor de Educação Física deverá dar ao esporte um tratamento pedagógico adequado, desenvolvendo-o de uma forma abrangente e diversificada, proporcionando ao aluno a oportunidade de conhecer, tomar gosto, aprender e manter o interesse pelo esporte.

O professor precisa eleger uma pedagogia que desenvolva as capacidades e habilidades, eduque atitudes, contribua para a construção da autonomia moral, que favoreça a autoestima e a socialização (SANTANA, 2012). Nesse sentido, o professor deve ser capaz de ensinar mais que competir, deve ensinar o aluno a gostar de esporte (FREIRE, 2003). Espera-se que o professor assuma uma postura educacional no tratamento da competição na escola e que tenha claros seus objetivos e métodos de trabalho (SOARES; MONTAGNER, 2013).

\section{Considerações Finais}


O esporte é um dos conteúdos mais hegemônicos da educação física, mas as suas reais possibilidades educacionais sempre estão sendo questionadas nas discussões acadêmicas. A questão é que muitas vezes o lado educacional do esporte é negligenciado, quando a escola utiliza uma pedagogia reducionista, tornando o esporte e as competições escolares cópias do esporte de rendimento, prevalecendo a ideia de ganhar a qualquer custo, do individualismo, enfatizando apenas os resultados. Este estudo buscou encontrar possíveis alternativas pedagógicas para o processo ensino aprendizagem do esporte e da competição nas aulas de Educação Física escolar baseado nos estudos da Pedagogia do Esporte.

A partir da análise nos artigos que abordam a presença do esporte e da competição na escola, mais especificamente na Educação Física, observou-se que muitos estudos abordam apenas o lado negativo do esporte e da competição. Em contrapartida, a Pedagogia do Esporte não ignora a existência dos aspectos negativos do esporte e da competição, mas também reconhece os seus aspectos positivos e as suas várias possibilidades educacionais. Verificou-se também, que o fracasso e o sucesso dos conteúdos do esporte e da competição dependem diretamente das condutas e princípios pedagógicos utilizados pelo professor.

Apesar da Pedagogia do Esporte apresentar diversas estratégias e possibilidades de desenvolver o esporte e a competição na Educação Física escolar, foi possível diagnosticar lacunas nesta temática.

Constatou-se a necessidade da elaboração de mais estudos de caráter práticos, que abranjam as diferentes modalidades esportivas, sobretudo as individuais, uma vez que identificou-se uma predominância nos estudos desta temática serem pautados a partir de modalidades coletivas, ou seja, a literatura precisa enfatizar mais nessa relação: teoria e prática. Diante disso, o presente estudo, contribui para abordar e destacar as diversas possibilidades educacionais do esporte a partir das propostas pedagógicas apontadas pela Pedagogia do Esporte.

\section{Referências}

AZEVEDO JÚNIOR, L. C. D. Esporte de competição escolar: uma análise do estresse situacional associado ao grau de coesão grupal. 2008. 96 f. Tese (Doutorado em Educação Física) - Universidade de São Paulo, 2008.

BALBINO H. F.; GALATTI, L. R.; FERREIRA, H. B.; PAES, R. R. Pedagogia do Esporte: significações da iniciação esportiva e da competição. In: REVERDITO, R. S.; SCAGLIA, A. J.; MONTAGNER, P. C. Pedagogia do esporte: aspectos conceituais da competição e estudos aplicados. São Paulo: Phorte, 2013. p. 41-68.

BARROSO, A. L. R.; DARIDO, S. C. A pedagogia do esporte e as dimensões dos conteúdos: conceitual, procedimental e atitudinal. Revista da Educação Física/UEM, v. 20, n. 2, p. 281-289, 2009.

BENTO, J. O. Da pedagogia do desporto. In: TANI, G.; BENTO, J.O.; PETERSEN, R.D.S. Pedagogia do desporto. Rio de Janeiro: Guanabara Koogan, 2006. p. 26-40.

BETTI, I. C. R. Esporte na escola: mas é só isso, professor. Motriz, v. 1, n. 1, p. 25-31, 1999. 
BRACHT, V; ALMEIDA, F. Q. A política de esporte escolar no Brasil: a pseudovalorização da educação física. Revista brasileira de ciências do esporte, v. 24, n. 3, p. 87-101, 2003.

BRASIL. Ministério da Educação e do Desporto. Secretaria de Educação Fundamental de 1 a 4 séries. PCNs Parâmetros Curriculares Nacionais: Educação Física. Brasília: MEC/SEF, 1997.

BELOTTO, C.; REVERDITO, R. S. Competição na Educação Física escolar: estudo etnográfico em uma turma de Ensino Fundamental. Motriz, Rio Claro, v.17, n.1, p. 44, 2011.

CARLAN. P.; KUNZ, E.; FENSTERSEIFER, P. E. O esporte como conteúdo da Educação Física escolar: estudo de caso de uma prática pedagógica "inovadora". Movimento, Porto Alegre, v. 18, n. 4, p. 55-75, 2012.

FREIRE, J. B. Pedagogia do futebol. São Paulo: Autores Associados, 2003.

GALATTI, L. R.; PAES, R. R. Fundamentos da pedagogia do esporte no cenário escolar. Movimento e Percepção, v. 6, n. 9, 2006.

GALATTI, L. R.; FERREIRA, H. B.; SILVA, Y. P. G.; PAES, R. R. Pedagogia do esporte: procedimentos pedagógicos aplicados aos jogos esportivos coletivos. Conexões: Revista da Faculdade de Educação Física da UNICAMP, v. 6, 2008.

GRAÇA, A.; MESQUITA, I. A investigação sobre os modelos de ensino dos jogos desportivos. Revista Portuguesa de Ciências do Desporto, v. 7, n. 3, p. 401-421, 2007.

HIRAMA, L. K.; MONTAGNER, P. C. Competição em Esportes: "ingrediente" para uma proposta formativa. In: REVERdito, R. S.; SCAGliA, A. J.; MONTAGneR, P. C. Pedagogia do esporte: aspectos conceituais da competição e estudos aplicados. São Paulo: Phorte, 2013. p. 315- 342.

MACHADO, G. V.; GALATTI, L. R.; PAES, R. R. Pedagogia do Esporte e o referencial histórico-cultural: Interlocução entre teoria e prática. Pensar a Prática, Goiânia, v. 17, n. 2, p. 414-430, 2014.

PAES, R. R. Educação física escolar: o esporte como conteúdo pedagógico do ensino fundamental. 1996. 198 f. Tese (Doutorado em Educação) - Faculdade de Educação, Universidade Estadual de Campinas, Campinas, 1996.

REVERDITO, R. S.; SCAGLIA, A. J. A gestão do processo organizacional do jogo: uma proposta metodológica para o ensino dos jogos coletivos. Motriz, Rio Claro, v. 13, n. 1, p. 51-63, 2007.

REVERDITO, R. S.; SCAGLIA, A. J.; SILVA, S. A. D.; GOMES, T. M. R.; PESUTO, C. L.; BACCARELLI, W. Competições escolares: reflexão e ação em Pedagogia do Esporte para fazer a diferença na escola. Pensar a prática, v. 11, n. 1, p. 37-45, 2008.

REVERDito, R. S.; SCAGLiA, A. J.; MONTAGneR, P. C. Pedagogia do esporte: aspectos conceituais da competição e estudos aplicados. São Paulo: Phorte, 2013. 462 p.

SADI, R. S. Temas da Pedagogia do Esporte, Educação Esportiva e Competições. Conexões: Revista da Faculdade de Educação Física da UNICAMP, v. 6, 2008.

SADI, R. S. Educação Física e Competição: crença no esporte educacional/escolar? In: REVERDITO, R. S.; SCAGLIA, A. J.; MONTAGNER, P. C. Pedagogia do esporte: aspectos conceituais da competição e estudos aplicados. São Paulo: Phorte, 2013. p. 99-122. 
SANTANA, W. C. Pedagogia do esporte na infância e complexidade. In: PAES, R. R.; BALBINO, H. F. Pedagogia do esporte: contextos e perspectivas. Rio de Janeiro: Guanabara Koogan, 2012. p.1-22.

SCAGLIA, A.; GOMES, R.M. O jogo e a competição: investigações preliminares. O jogo dentro e fora da escola. Campinas, SP: Autores Associados, 2005.

SCAGLIA, A. J.; MEDEIROS, M.; SADI, R. S. Competições Pedagógicas e Festivais Esportivos: questões pertinentes ao treinamento esportivo. Revista Virtual EFArtigos, Natal/RN, v. 3, n. 23, abril, 2006.

SOARES, F. C.; MONTAGNER, P. C. A OCESP e o discurso da Educação Física sobre a competição. In: REVERDito, R. S.; SCAGLiA, A. J.; MONTAGneR, P. C. Pedagogia do esporte: aspectos conceituais da competição e estudos aplicados. São Paulo: Phorte, 2013. p. 259-314.

STIGGER, M. P. Relações entre o esporte de rendimento e o esporte da escola. Revista Movimento, Porto Alegre, v. 7, n. 14, p. 67- 86, 2001.

VARGAS, T.; MORISSO, M. M.; GONZÁLEZ, J, F. O ensino do esporte utilizando o modelo sport education o relato de uma experiência. P. 277-294. In: DARIDO, S. C. Educação Física no ensino médio. Ijuí: Unijuí, 2017

VARGAS, T.; MORISSO, M. M.; GONZÁLEZ, J, F.; SALWITZKI, R. S. A experiência do sport education nas aulas de Educação Física: utilizando o modelo de ensino em uma unidade didática de futsal. Revista Movimento, v. 4, n. 3, p. 735-748, 2018.

VENDITTI JR, R.; SOUSA, M. A. Tornando “o jogo possível”: reflexões sobre a Pedagogia do Esporte, os fundamentos dos jogos desportivos coletivos e a aprendizagem. Pensar a Prática, v. 11, n. 1, p. 47-58, 2008.

\section{Como citar este artigo}

FARIA, Flaviane; CAREGNATO, André Felipe; CAVICHIOLLI, Fernando Renato. O esporte e a competição na educação física escolar: perspectivas educacionais a partir dos conceitos da pedagogia do esporte. Revista Kinesis, Santa Maria, v. 37, p.01-12, 2019. 